\title{
An infographic of data sharing in North America
}

\author{
Amédé Gogovor ${ }^{1}$ \\ ${ }^{1}$ Postdoctoral Researcher, Université Laval, Quebec, Canada \\ Corresponding author: amede.gogovor.1@ulaval.ca
}

\section{Description}

In this infographic, a comparative data sharing policy in Canada and United States is shown. It focuses on data policy recently released by the main public research funding agencies in both countries: the Tri-Agency in Canada and the National Institutes of Health in United States. Data sharing is one of the pillars of Open Science, defined as the sharing of all information related to research. ${ }^{1,2}$

I developed this infographic, as part of the EPI 7913 course "What You Need to Know About Journalology: The Science of Academic Publishing" (www.uottawa.ca/course-timetable/), to contribute to the awareness on data sharing and on Open Science in general. For the creation of the infographic, I gathered data from the EPI 7913 course material. I also conducted targeted searches on bibliographic databases and relevant websites on the topic. The initial version of the infographic benefited from feedback from the EPI 7913 course instructors and students. For the design of the infographic, I used the free version of Canva (canva.com).

\section{References}

1. Bartling Sn, Friesike S. Opening science : the evolving guide on how the Internet is changing research, collaboration and scholarly publishing. Heidelberg : Springer Open; 2014.

2. Wilson M, Moher D. The Changing Landscape of Journalology in Medicine. Semin Nucl Med. 2019;49(2):105-14.

\section{Supplemental materials}

https://osf.io/3vqcj/

\section{Funding}

AG is supported by a CIHR Patient-Oriented Research fellowship. 